\title{
Louise Bourgeois y el canon modernista en Historia del Arte: Alternativas desde la crítica feminista
}

\author{
Esther SÁNCHEZ-PARDO GONZÁLEZ \\ Universidad Complutense de Madrid \\ esanchez_pardo@filol.ucm.es
}

Recibido: 1.11.2013

Aceptado: 19.11.2013

\begin{abstract}
RESUMEN
Louise Bourgeois comenzó su carrera artística en Nueva York en los años 40 como colega de los pintores del expresionismo abstracto, grupo cuya obra fue recibida y valorada por críticos como Clement Greenberg como la cima de la abstracción modernista. La posición peculiar de Bourgeois -a caballo entre dos movimientos artísticos aparentemente opuestos: surrealismo y expresionismo abstracto por un lado, y feminismo por otro- ha resultado ser un problema para la crítica. A medida que los historiadores del arte han empezado a desdibujar los límites que separan al modernismo del arte feminista, la obra de Bourgeois ha cobrado nueva vigencia.

En este artículo sugerimos que la obra artística de Bourgeois elaboró ampliamente tropos vanguardistas para el inconsciente y lo femenino para llegar a subvertir la identificación sexista y simplista de feminidad con irracionalidad. También incluimos un comentario extenso sobre su instalación "Precious Liquids" (1992) que se sitúa en la historia del arte en el seno de los debates en torno al potencial metafórico del cuerpo, explorando lo que en ella se deriva del expresionismo abstracto así como de las propias esculturas de piedra y goma de la artista.
\end{abstract}

Palabras clave: Louise Bourgeois, canon modernista, crítica de arte feminista, expresionismo abstracto, "Precious Liquids"

\section{Louise Bourgeois and the modernist canon in Art History: Alternatives from feminist criticism}

\begin{abstract}
Louise Bourgeois began her artistic career in New York in the 1940s as a colleague of the abstract expressionists, whose artwork was hailed by Clement Greenberg as a high point in modernist abstraction. Bourgeois' peculiar position -poised between two seemingly opposed art movements, surrealism and abstract expressionism and feminism- has created a conundrum for critics. As art historians have increasingly begun to blur the boundaries separating modernism from feminism, however, Bourgeois' art has acquired fresh urgency.

In this paper we suggest that Bourgeois' artistic oeuvre elaborated avant-garde tropes for the unconscious and for women in order to posit a complex female subjectivity and to challenge the simplistic identification of irrationality with femininity. We also provide a critical approach to her installation "Precious Liquids" (1992) in the midst of feminist art historical debates around the metaphorical potential of the body drawing
\end{abstract}


from the painted traces of the abstract expressionists and from the artist's own previous rubber and stone sculptures.

Keywords: Louise Bourgeois, modernist canon, feminist art criticism, abstract expressionism, "Precious Liquids"

La producción artística de Louise Bourgeois (1911-1010) abarca un periodo superior al medio siglo, desde sus inicios en el expresionismo abstracto de los años 40 hasta el mundo artístico plural y globalizado actual, pasando por la eclosión del movimiento artístico de mujeres de los años 70 , y ofrece una amplia perspectiva sobre la evolución y la institucionalización del arte occidental desde la Segunda Guerra Mundial hasta nuestros días.

Sin duda, Bourgeois llega a ser conocida por el gran público a raíz de su participación en los movimientos artísticos feministas de los años 70 , en los que artistas y escritoras desarrollaron una intensa campaña de cuestionamiento de la ortodoxia patriarcal imperante en el arte. La crítica feminista Lucy Lippard quiso subrayar el papel de Bourgeois en este movimiento utilizando una de las pinturas de la serie de postguerra "Femme-Maison" de Bourgeois, en la que representa a una mujer desnuda y de pie, con una casa en lugar de cabeza, como portada de su influyente volumen From the Center. Feminist Essays on Women's Art (1976). Su arte de esa época se rebela contra la abstracción minimalista imperante, contraponiendo una serie de esculturas semiabstractas de aspecto viscoso en yeso y caucho. En su instalación de 1974 "The Destruction of the Father" ("La destrucción del Padre") presenta una fantasía de venganza contra un patriarca opresivo. Dos años más tarde en "Confrontation: A Performance/ A Fashion show of body parts" ("Confrontación: Una Performance / Show de moda de partes corporales") presentaba a diversas figuras destacadas del mundo del arte en Nueva York paseándose con trajes de látex con protrusiones fálicas o mamarias que anulaban sus habituales aires de autoridad.

Con estas credenciales feministas, parece extraño que su carrera empezase coetáneamente con la de los expresionistas abstractos, Rothko y Pollock entre otros, cuya obra, irónicamente, llegó a ser considerada como el mejor ejemplo de la abstracción minimalista. Bourgeois se instaló en Nueva York en 1938 tras su matrimonio con el historiador de arte Robert Goldwater. Durante los años siguientes se mezcló con los círculos del expresionismo abstracto, participando activamente en exposiciones $y$ foros colectivos, adquiriendo un cierto reconocimiento en los círculos de vanguardia, y en 1951 el MOMA adquirió su escultura "Sleeping Figure" (1950) ("Figura durmiente"). Tradicionalmente se han contrapuesto los valores propugnados por el arte y crítica feministas (que subrayan la inversión personal del individuo en el arte) con los valores del modernismo (que 
la ocultan tras un ideal de autonomía y universalidad) preconizados por Clement Greenberg al afirmar que el arte moderno se debe "limitar a lo aportado en la experiencia visual y no hacer referencia a ningún otro orden de experiencia" (Greenberg, 1966: 74). Esta idea se vio refrendada por una gran mayoría de críticos contemporáneos, que desarrollaron una mitología de la autonomía y trascendencia del expresionismo abstracto que en las décadas sucesivas primó la abstracción por encima del resto, y que fue contraria a cualquier compromiso político o personal en el arte.

En los años 70, cuando artistas y escritoras feministas empezaron a cuestionar este rígido formalismo, Louise Bourgeois parecía satisfacer la necesidad de un modelo de artista feminista de más edad y la de ser una alternativa a los valores formalistas defendidos por Greenberg y otros. Sus esculturas, que escapaban a cualquier categorización, así como su afirmación repetida de que su obra da forma física a las sensaciones y conflictos del inconsciente, se oponían frontalmente al ideal modernista. En palabras de Lucy Lippard "raramente el arte abstracto ha sido informado tan directa y honestamente por la psique de su autor" (Lippard, 1976: 238).

Alentada por la recepción de su obra por parte del público feminista, Bourgeois comenzó a presentar su arte en términos cada vez más personales y autobiográficos, como forma de luchar contra las incertidumbres y pérdidas de la vida, y como terapia frente a las ansiedades de una niñez presidida por el adulterio entre su padre y la institutriz inglesa de Louise, conocido y tolerado por su madre. Sus vívidos relatos de la niñez, y de su efecto en su arte, han tenido como consecuencia el desarrollo de un auténtico culto a su personalidad, sin que esto haya resultado necesariamente en una mejor comprensión de su arte, que a menudo se contempla de modo simplista como el resultado de una obsesión patológica con recuerdos de su niñez. El mayor problema de esta crítica anecdótica basada en acontecimientos biográficos es que difícilmente puede explicar el poder evocativo de su arte, altamente abstracto en su mayoría, o las poderosas emociones que desencadena en el espectador, desde el temor y la repulsa a la melancolía (Serra, 1994: 80; Piper, 1994: 79).

Para situar la obra de Louise Bourgeois en su contexto dentro del arte actual, manejaremos varias ideas. En primer lugar, la Bourgeois que llegó a Nueva York después de la Guerra, al igual que sus colegas masculinos de Nueva York, estaba fuertemente comprometida con las ideas surrealistas sobre lo irracional y lo inconsciente en la subjetividad humana. Este grupo se embarcó en un esfuerzo colectivo para elaborar un sistema de metáforas visuales en torno al inconsciente. Estos artistas americanos adoptaron la convicción surrealista de que los procesos psíquicos inconscientes generan una temática artística muy fértil, si bien 
rechazaron la técnica pictórica ilusionista de los surrealistas de primera generación, como Dalí y Magritte, para adoptar en su lugar los ejemplos más abstractos de Masson, Miró y Matta. Aspiraban a explotar el potencial expresivo de la abstracción para llegar a una analogía visual más válida, espontánea y "automática" de los materiales y procesos psíquicos inconscientes.

Un número creciente de académicos revisionistas del expresionismo abstracto han cuestionado desde los años 70 el relato formalista del "high modernism" y han reintroducido y extendido enfoques interpretativos que habían sido suprimidos durante años. Entre los más tempranos antagonistas de las ideas de Greenberg podemos citar a Cavaliere y Hobbs (Cavaliere y Hobbs, 1977) cuando argumentan que "la verdadera fuente de los impulsos creativos de los años 40 fue el intenso deseo de los artistas por comunicar ideas significativas y evocativas en un formato abstracto", y entre las fuentes de los temas del expresionismo abstracto citan los intereses de los artistas en el surrealismo, la mitología griega, el arte primitivo, y "nuevas imágenes del hombre" (Cavaliere y Hobbs, 1977: 110, 111) para finalmente lamentar que: "es un caso de ironía extrema que el primer y más articulado apólogo de la nueva pintura, Clement Greenberg, haya ignorado la implicación en la temática proclamada de los propios artistas, y se haya negado a entender estas pinturas en términos distintos a los estrictamente formalistas" (Cavaliere y Hobbs, 1977: 114). También a finales de los 70, después de que salieran a la luz las transcripciones de las sesiones analíticas a las que se sometió Jackson Pollock, apareció un gran número de interpretaciones de sus primeras pinturas en clave de simbolismo Jungiano (por ejemplo, Langhorne, 1979).

Existe un número creciente de trabajos que analizan los modelos de subjetividad que operan en el arte expresionista abstracto (véanse Chave, 1989; Gibson, 1977; Leja, 1993). Entre ellos destaca el controvertido estudio de Anna Chave sobre Rothko, en el cual considera que su principal tema pictórico es la propia subjetividad, al tiempo que descubre diferentes temas presentes en su obra, incluyendo ideas surrealistas acerca del inconsciente, la idea del "drama humano" de Nietzsche, y temas religiosos. De modo similar, Ellen Landau compara el acercamiento de Pollock al arte con el "método" de actores como Brando y Dean, que profundizan en su psique y usan sus propios cuerpos y sentimientos con espontaneidad y fuerza en la búsqueda de la verdad interior (Landau, 1989: 15).

Martica Sawin y Paul Schimmel, entre otros, han revisado recientemente las relaciones conceptuales y estilísticas entre surrealismo y expresionismo abstracto, relaciones que durante años fueron obviadas por Greenberg y los críticos formalistas (Schimmel, 1986; Sawin, 1995). 
No obstante, la hegemonía de la concepción formalista del expresionismo abstracto y la narrativa de heroísmo y trascendencia que le acompaña no han sido fácilmente desmanteladas. La idea de un nuevo movimiento artístico de éxito, concreto, y característicamente americano, respondía a la necesidad de un símbolo de afirmación de la identidad y la preeminencia americanas en la postguerra. Es cierto que existía una cierta creencia generalizada de que los artistas americanos podían llega a ser líderes en el mundo del arte, pero los propios artistas aspiraban más a adquirir una significación internacional que a cualquier tipo de identidad nacionalista provinciana, $\mathrm{y}$, de hecho, la retórica modernista del triunfo se formuló de manera retrospectiva, y pudo tener más que ver con los deseos de los críticos y del público que con las circunstancias de la producción artística o de sus características visuales. La mayoría de las obras canónicas del expresionismo abstracto fueron creadas entre 1947 y 1950, y los ensayos más influyentes de Greenberg datan de los años 60, siendo el primero de 1955 (Greenberg, 1955)

No obstante, el factor más significativo en la permanencia de la interpretación formalista del expresionismo abstracto fue probablemente su simplicidad y coherencia, una coherencia de la que carecen las interpretaciones revisionistas, como hemos visto con anterioridad. La variedad de temas que se originan en la psique o en los sentimientos es difícil de explicar. La compleja relación entre arte e inconsciente es otro obstáculo importante. Los propios artistas, incluida Louise Bourgeois, han afirmado que pueden de algún modo acceder directamente al contenido oculto de la mente inconsciente y hacerlo visible de forma no mediatizada, casi mágica. Estas afirmaciones van en contra de las propias bases del psicoanálisis, que postula que las fuerzas inconscientes sólo pueden manifestarse de forma indirecta. Pese a ello han sido repetidas por algunos de los académicos revisionistas. La propia validez del psicoanálisis como herramienta de interpretación es objeto de controversia. Numerosos críticos, entre ellos muchas críticos feministas, han criticado la teoría freudiana clásica en sus dogmas anticuados y perniciosos de inherente "pasividad" y "envidia del pene" por parte de la mujer. Por otra parte, la crítica feminista también ha implementado el psicoanálisis clásico como medio para diagnosticar y desmantelar mitologías patriarcales, contribuyendo a la evolución moderna del psicoanálisis, en su intento por corregir y modificar los sesgos freudianos del siglo XX.

Un primer acercamiento a la obra de Louise Bourgeois debería comenzar en el análisis de las principales metáforas visuales del inconsciente que la artista y sus colegas expresionistas abstractos emplearon en el periodo en torno a la Segunda Guerra Mundial. Pese a que el surrealismo no fue la única influencia en la evolución del arte de Bourgeois, su importancia para los desarrollos posteriores es crucial. Y pese a que el "inconsciente" no es el único concepto aplicado por las 
vanguardias en esa época, es el centro de gravedad alrededor del cual giran el resto de temas, como surrealismo, primitivismo y mitología.

Las tres principales metáforas visuales que se encuentran en su arte de esta época son esencialmente: imágenes de cajas que contienen objetos enigmáticos, evocaciones de profundidades ocultas, e imaginería biomórfica. El primer grupo representaría lo inconsciente como un mundo aparte, normalmente oculto a la vista, y cuyo contenido misterioso requiere ser interpretado. El segundo funciona como un análogo visual de la caracterización freudiana del psicoanálisis como psicología "profunda", tanto espacial como temporalmente. Por último las imágenes biomórficas de formas animales y vegetales se refieren metafóricamente a un yo instintivo o "natural", un yo que es también "arcaico" o "primitivo". Cuando estos temas se consideran a la vez, resulta evidente que cada uno se refiere metafóricamente a los otros, creándose así una cadena de referencias que se autorefuerza. Además, cada una de estas metáforas es ambivalente, mostrando el inconsciente como fuerza a la vez vital y amenazadora, como fuente de poder y creatividad y a la vez origen de violencia, caos y desintegración. A causa de esta ambivalencia es fácil comprender por qué los artistas, principalmente varones blancos, tienden a identificar el inconsciente con un "otro" supuestamente primitivo, como pueblos "arcaicos" o no occidentales, y formas de vida no humanas, mientras que se reservan su poder como creadores varones, euroamericanos, civilizados (= no nativos).

Pero el arte de Bourgeois en la postguerra reinterpreta los tropos del inconsciente tan populares en las vanguardias problematizando la identificación simplista de "mujer" con irracionalidad, y en su lugar postula una subjetividad femenina compleja, irracional y a la vez racional. Su serie "Femme-Maison" invoca inteligentemente los tropos convencionales que asimilan el inconsciente a un "otro" primitivo o femenino, y los coloca en sus cabezas. Cada una de sus Mujeres-Casa se presenta atrapada dentro de una casa-caja que literalmente sustituye a la cabeza, el asiento tradicional de la racionalidad y el reconocimiento, por un símbolo convencional del inconsciente. Pero en contraste con las imágenes del surrealismo y del expresionismo abstracto que localizan el inconsciente en un pasado arcaico y mitológico, Bourgeois utiliza imágenes más cercanas, evocando un proceso personal y social de desarrollo psíquico.

Atención especial merece el análisis de la producción escultural de Bourgeois desde finales de los años 40 y de la tensión dinámica entre representación convencional y búsqueda de espontaneidad en su conjunto. Como sus colegas del expresionismo abstracto, desde finales de los años 40 emplea estrategias de representación cada vez más abstractas, con la convicción -algo inocente- de que ello permitiría transmitir el contenido consciente e inconsciente de forma directa y 
universalmente accesible. Mientras sus primeras esculturas abstractas mantienen referencias claras a su niñez, progresivamente van dando lugar cada vez más a evocaciones más sutiles de percepciones y emociones infantiles, así como estados psíquicos del ser en la acepción psicoanalítica.

Finalmente, debemos incidir en la relación de Bourgeois con la crítica feminista contemporánea. El papel del cuerpo en su obra ha enfrentado a críticos a ambos lados de uno de los grandes temas a debate en teoría feminista. Por un lado, los que invocan su arte para celebrar la feminidad, por otro, los que lo utilizan para criticar la idea de una identidad femenina de base biológica. Este conflicto se ejemplifica en las interpretaciones dispares por parte de MarieLaure Bernadac y de Griselda Pollock de la instalación "Precious Liquids", expuesta por primera vez en la Dokumenta de Kassel en 1995. En el centro de este debate se encuentran los significados de la metáfora que da nombre a la instalación: un charco de líquido sobre una cama vieja y desvencijada dentro de un espacio oscuro del tamaño de una habitación. Bernadac identifica el líquido como fluido amniótico, celebrando el cuerpo materno como símbolo de creatividad y "renacimiento artístico". Pollock, por el contrario, advierte del peligro de querer subsumir deseo, subjetividad y diferencia sexual en una identidad corporal en la que la única forma de pensar en la diferencia femenina sea a través de la especificidad del cuerpo materno, y pone énfasis en la ausencia del cuerpo en la instalación, comparándola en su lugar con la evocación mecanística del cuerpo por medio de sus fluidos en "The Large Glass”, de Marcel Duchamp (Bernadac, 1996: 137; Pollock, 1999: 76)

Ambos extremos del debate crítico niegan al cuerpo su gran capacidad para la metáfora. ¿Por qué no es posible leer el significante líquido del cuerpo y del nacimiento físico como una metáfora del "nacimiento psicológico" y de la continua fluidez de una subjetividad emergente? Si las visiones primordiales de los expresionistas abstractos pueden representar el legado "prehistórico" de la infancia preverbal, ¿no podría funcionar el cuerpo materno como una metáfora del self "primitivo" intersubjetivo?

El papel del cuerpo en el arte de Bourgeois ha reclamado la atención de críticas y teóricas que se sitúan a ambos lados del conflicto crítico en la teoría feminista contemporánea, confrontando aquellas que situarían el arte de Bourgeois celebrando lo femenino frente a las que lo opondrían a cualquier noción de identidad femenina esencial. La línea que separa a las feministas "esencialistas" de sus colegas "constructivistas" o desconstructivistas se abre progresivamente sobre el mismo terreno del que se separa el formalismo modernista -las arenas movedizas de la subjetividad corpórea y encarnada. ¿Acaso el abismo teórico que deja a Bourgeois suspendida entre estos dos polos del feminismo podría tener un 
efecto directo sobre el relativo abandono de la consideración de su obra por parte de las teóricas modernistas?

Louise Bourgeois ocupa una posición peculiar en el mundo del arte hoy. Fallecida en 2010, continuó trabajando con intensidad prácticamente hasta el final de sus días. Ni su productividad ni su reputación experimentaron descenso a edad tan avanzada, y de hecho la consideración de su trabajo creció exponencialmente. Diez años después de su "entrada oficial en el canon del arte Euroamericano" el Museo Guggenheim inauguró su filial del SoHo en 1992 con una exposición titulada, "From Brancusi to Bourgeois." Ese mismo año fue invitada a crear una instalación para la Dokumenta IX de Kasseladquirida con posterioridad por el Musée Nationale d'Art Moderne de Paris. En 1993 representó a EEUU en la Bienal de Venecia. Y cuando la galería Tate Modern fue inaugurada en Londres en el año 2000, la primera exposición que el Museo encargó fue un juego de tres torres monumentales en acero de Bourgeois. Durante el verano de 2001, un trio de las arañas gigantes de Bourgeois presidió el Rockefeller Center. Finalmente, la más grande de estas tres figuras fue instalada frente al Hermitage en St. Petersburgo donde a la artista se le dedicó una retrospectiva durante tres meses ${ }^{2}$.

Y a pesar de esta presencia en lugares tan prestigiosos a nivel mundial, Bourgeois sigue siendo fundamentalmente una exiliada, una artista sin coordenadas diferenciadas en el vasto terreno de la historia del arte. Entre cientos de exposiciones y de volúmenes dedicados al "Expresionismo Abstracto" a lo largo del siglo XX, Bourgeois sigue estando infrarrepresentada. De manera aún más sorprendente, la atracción que suscitó en el seno del feminismo de los años 70 , no desencadenó inmediatamente una oleada de crítica feminista en torno a su obra, si nos referimos a opiniones como las de Griselda Pollock al respecto. A finales de los 70, como señala Pollock, había "mucho que hacer para desarrollar el doble frente de la desconstrucción feminista de la historia del arte masculinista así como de la reconstrucción feminista de los contradiscursos por medio de los cuales se analizan las prácticas artísticas, intervenciones y procesos de las artistas mujeres" (Pollock, 1999: 85). Aún así, y teniendo en cuenta el volumen de crítica feminista que queda por hacer no parece que el feminismo solo sea capaz de dar cuenta de esta gran laguna. La singularidad del papel de Bourgeois como mujer cuya carrera se extiende durante más de cinco décadas del siglo XX, cuyo trabajo ha cuestionado sistemáticamente la relación entre subjetividad, sociedad y

1 Pollock fue quien denominó de esta manera la primera exposición retrospectiva que el MOMA de Nueva York montó sobre la obra de Bourgeois en 1982 (Pollock, 1999: 75).

2 Bourgeois fue la protagonista de un artículo que Joan Acocella publicó en The New Yorker en 2002, ensayo que enumera todos los lugares recientes de su itinerario de éxito (Acocella, 2002). 
diferencia sexual, y que continúa generando un arte sorprendente y provocativo durante los años noventa, reclama un análisis histórico e informado por la teoría.

La producción artística de Louise Bourgeois franquea los limites tradicionales de la historia del arte incluyendo los del modernismo y feminismo si bien esta apertura se convierte en un obstáculo cuando se trata de inscribir y situar a la artista en el lugar que le "corresponde" en la historia del arte. La trayectoria de Bourgeois y su vínculo con la Escuela de Nueva York, le otorgan un aura de prestigio difícilmente alcanzable por cualquier otra artista de su generación. Una institución (como el Guggenheim, SoHo o la Tate Modern), conocida por asumir riesgos sin abandonar su autoridad institucional, puede en cierta medida apoyar la carrera de artistas menos conocidos al tiempo que apoya a artistas más establecidos como fue el caso de Bourgeois. Pero si "la historia de la mayoría de los artistas que llegan al canon tiene que ver con su vinculación a un momento significativo" (Pollock, 1999: 87) el artista que no "encaja" amenaza la integridad de la narrativa de la historia del arte construida en base a una progresión de "movimientos" históricos.

La creación de Bourgeois se extiende durante más de cinco décadas, su forma de dar significado artístico a los miedos, fantasías secretas y deseos de las mujeres, así como su constante introspección y exploración del pasado, constituyeron un atrayente modo de creación para el Movimiento Feminista, que otorgó a su obra un carácter político, ya que toda su producción está atravesada por esa conciencia de la diferencia sexual, por la polaridad Padre-Madre, que surge continuamente en sus creaciones. Fue en estos círculos feministas donde su figura y su obra comenzaron a tener visibilidad antes de su reconocimiento internacional.

Las tensiones que contribuyen a la frágil posición de Bourgeois en la historia del arte se ponen de manifiesto en un número especial que el Oxford Art Journal dedicó a la artista (Nixon, 1999). La incómoda alianza de Bourgeois con el modernismo es el objeto de la crítica feminista de arte Griselda Pollock en su ensayo "Bourgeois and the Problem of Age" que, no obstante, también reúne los debates feministas en torno al cuerpo y al papel de Bourgeois en la historia del arte de mujeres. En el centro del debate se encuentra su instalación "Precious Liquids" (1992), y la correcta interpretación de la metáfora contenida en el título de la misma ${ }^{3}$. Marie-Laure Bernadac la experta francesa en Bourgeois, ha identificado el "líquido precioso" de Bourgeois con líquido amniótico, en exaltación del cuerpo materno y de la creatividad femenina. Pollock, que advierte contra el "peligro de colapsar deseo, subjetividad y diferencia sexual en una mera identidad corpórea", pone énfasis por el contrario en la ausencia del cuerpo en la instalación de

37 "Precious Liquids" se puede ver en Bernadac (1996: 136). 
Bourgeois, comparándola con la "evocación mecanística del cuerpo a través de sus fluidos" en "The Large Glass" de Duchamp.

Este no es más que el inicio de los debates a que ha dado lugar "Precious Liquids". Desde su retrospectiva en el MOMA, la obra de Bourgeois ha incorporado cada vez más instalaciones ambientales de gran tamaño. Al mismo tiempo que tales instalaciones señalan un alejamiento de medios más simples como la pintura y la escultura, empleados por Bourgeois en periodos anteriores de su carrera, también representan una continuación -o mejor, una amplificación- de los temas y los medios habituales en Bourgeois. Como tal, "Precious Liquids" retoma y sintetiza los traumas y placeres de la subjetividad encarnada.

Los debates en torno a "Precious Liquids" ilustran las ansiedades que el arte de Bourgeois despierta en los historiadores del arte profesionales. ¿Es su arte modernista o antimodernista? ¿Debe interpretarse como una exaltación de la subjetividad femenina corporeizada, o como una crítica de las determinaciones de la identidad basadas en criterios biológicos? A otro nivel, los intentos de distinguir y fijar estas categorías de la historia del arte, y el arte de Bourgeois dentro de ellas, dejan traslucir una ansiedad que va más allá de un problema de genealogía académica hasta llegar al problema de la propia subjetividad.

El objeto de la controversia, "Precious Liquids", fue creado por Bourgeois para la Dokumenta IX de Kassel en 1992, y fue posteriormente adquirida por el Musée Nationale d' Art Moderne de París. El exterior de la instalación, en forma de tonel, procede de una antigua torre de agua en madera de sequoia, de las que se encontraban habitualmente en los tejados de la ciudad de Nueva York en los años 40. Tal como se instaló en Kassel, ese barril del tamaño de una habitación llenaba completamente el fondo de un pasillo. Su exterior, con aspecto de fortaleza, recuerda, como apunta Pollock, las imponentes puertas de madera de los "Étant Donnés" de Duchamp. Pese a ello, observando atentamente, se distingue una puerta pequeña que permite acceder a su oscuro interior.

Al cruzar el umbral, la espectadora se encuentra dentro de un recinto de techo muy alto y medio en penumbra. Nos hallamos dentro de un enorme tonel, por cuyo interior podemos transitar. Al fondo, observamos una cama de hierro en cuyo centro hay un pequeño charco de agua y en cuyas esquinas encontramos cuatro barras de metal de las que cuelgan diversos recipientes de vidrio. Según sus palabras, el vidrio es un símbolo de lo femenino en el que se unen resistencia y fragilidad. Frente a la cama se sitúan dos bolas de caucho y una escultura de alabastro; al otro lado, un perchero de madera del que cuelga un abrigo de caballero, y en su interior se esconde un pequeño vestido de niña con las palabras bordadas "Merci/Mercy", jugando con el doble significado en francés e inglés "Gracias/Piedad." La escultura de alabastro lleva por título "Trani Episode (1971- 
72)" y en la obra de Bourgeois ha pasado por varias versiones, materiales y formatos. La que nos ocupa es blanca: dos cilindros esféricos superpuestos de apariencia suave y moldeable caen uno sobre otro, en clara alusión al sexo femenino.

Las instalaciones de Bourgeois de esta época combinan temas clásicos y presentes en su trabajo desde un principio, con una capacidad creativa e imaginativa sorprendente. Como ocurrió con las instalaciones que la artista realizó en la galería Peridot años atrás, "Precious Liquids" plantea, por así decir, un desvelamiento de objetos internos que pueblan un paisaje psíquico enormemente significativo. Todos estos objetos rememoran la casa de infancia de Bourgeois y funcionan a la vez como recordatorio de figuras muy cercanas en los afectos así como de elementos presentes en el telar de restauración de la familia. Toda la parafernalia que rodea a la cama que preside la estancia recuerda los instrumentos de un taller de tejidos: sus columnas verticales con ganchos que soportan los hilos, así como la estructura de la maquinaria artesanal utilizada por los Bourgeois. En cualquier caso resulta más apropiado entender todos estos elementos como objetos imaginarios en base a sus semejanzas con otros elementos presentes en paisajes y ambientes imaginaros, que en base a la relación que guardan con objetos reales. De modo que en la penumbra de ese tonel cilíndrico experimentamos una confrontación semi-onírica con presencias del orden de la fantasía inconsciente.

Puede decirse que el interior de "Precious Liquids" contiene una retrospectiva íntima de los principales motivos formales y simbólicos de la obra de Bourgeois. El panelado vertical del tonel evoca un bosque frondoso, así como la estructura metálica que rodea la cama remite a los árboles, con frutos que penden de sus ramas, y a la decoración que el boj podado y arreglado aportaba al exterior de la casa familiar. Así mismo los bloques de distintos materiales que rodean la estancia remiten a la lápida de la tumba de su abuela, ya presente en su lienzo "Reparation." Sobre el suelo de la instalación, las formas redondeadas nos remiten directamente a la trayectoria artística y metafórica de Bourgeois y nos llevan a pensar en esa especie de excrecencias de goma de "Destruction of the Father", a los brotes tiernos de "Cumul I", e incluso antes de eso a la proliferación de bebés que surgen del cuerpo de la madre en los primeros cuadernos de bocetos de Bourgeois. Todos los componentes simbólicos de la familia nuclear también están representados en el enorme abrigo colgado del perchero, en la estructura redondeada y de apariencia blanda, "Trani Episode", así como en la cama humedecida.

Es precisamente la cama y su contenido lo que ha venido a protagonizar el centro del diálogo entre dos críticas de arte Marie-Laure Bernadac y Griselda Pollock, conocedoras de la obra de Bourgeois, e interesadas en promover la crítica 
feminista, así como la investigación y publicaciones sobre la obra de Bourgeois. En cada uno de los casos, los argumentos de ambas giran en torno a la posición de Bourgeois en relación al canon modernista -representado, p.ej. por "The Large Glass" de Duchamp. Bernadac sitúa a la obra de Bourgeois como "inversa" a la "seca esterilidad" de Duchamp, argumento muy representativo de una rama del feminismo que celebra la identidad y la experiencia femenina al tiempo que la valora como alternativa

Precisamente la cama mojada que ocupa el centro de la habitación interior de la instalación es lo que conforma el núcleo de la controversia entre ambas lectoras, Bernadac y Pollock, cada una de ellas afirmando representar los intereses del feminismo, así como los del estudio académico de Bourgeois. En ambos casos, los argumentos de cada autora oscilan en torno al lugar que ocupa Bourgeois en relación al modernismo, representado por una obra canónica de Duchamp, "The Large Glass". Para Bernadac, la obra de Bourgeois constituye un "colgante femenino e inverso" en relación a la "esterilidad seca" de Duchamp, razonamiento que es ampliamente representativo de una rama del feminismo que exalta la identidad, experiencia, y valores femeninos como alternativa positiva a los valores de la masculinidad y del modernismo dominado por los hombres (Bernadac, 1996: 135, 136). Por el contrario, Pollock opta por sugerir una relación más complicada entre feminismo y modernismo, proponiendo que la instalación de Bourgeois "recupera y realinea 'en lo femenino" el potencial no del todo comprendido del arte de Duchamp (Pollock, 1999: 82). Para Bernadac, el "líquido precioso" de Bourgeois marca la presencia de un cuerpo, una presencia que identifica como femenina, poderosa y creativa. Para Pollock, la esencia es la ausencia del cuerpo, una ausencia que permite la deconstrucción de las determinaciones de identidad sexual basadas en el cuerpo.

Examinemos con más atención los argumentos de Bernadac y Pollock. Bernadac fue la primera en avanzar una interpretación de la instalación en su monografía de 1996 sobre Bourgeois, aunque tanto su lectura como la de Pollock están informadas por una interpretación todavía más temprana, la de Rosalind Krauss. Krauss compara toda la obra de Bourgeois con "The Large Glass" de Duchamp en su ensayo de 1989 "Portrait of the Artist as Fillette" ("Retrato de la artista como Fillette") (Krauss, 1989). Krauss sugiere que la escultura de Bourgeois, como "The Large Glass" de Duchamp, o alternativamente "La mariée mis a un par ses celibaires, même", pone en práctica la lógica de una "machine célibataire" ("máquina soltera"): "más allá del ciclo de fecundación / nacimiento / vida / muerte, constituyen tanto un sueño de celibato infinito como uno de autoerotismo total". Bernadac acepta la comparación entre Bourgeois y Duchamp como un cumplido, pero le da la vuelta al argumento al afirmar que si el arte de Duchamp representa masculinidad y modernidad en toda su esterilidad, entonces 
Bourgeois, por el contrario, representaría la fecundidad de una alternativa femenina:

"Lo llano de "Large Glass" se contrarresta con el volumen de "Precious Liquids", la transparencia se contrarresta con oscuridad, y la seca esterilidad de la soltería con la húmeda fecundidad de la maternidad (sugerido por el abrigo masculino "embarazado", las dos pelotas, los pechos de "Trani Episode", el líquido en la cama evocando el fluído amniótico del nacimiento o, en el caso de Bourgeois, del renacimiento) (Bernadac, 1996: 137).

Destacan dos aspectos de la argumentación de Bernadac: primero, la importancia capital del cuerpo, y especialmente del cuerpo materno, como "garantía" de la identidad de la artista y del significado de su obra, y en segundo lugar, la insistencia de que ambos, identidad y significado, sean comprendidos como plenamente positivos -fértiles, reproductivos, regeneradores. Supuestamente, cada elemento de la instalación pone en escena la "maternidad" incluso el enorme abrigo de hombre que, de hecho, oculta en su interior un vestido de niña pequeña bordado con las palabras "Merci / Mercy". Esta maternidad simbólica significa, para Bernadac, el éxito personal y artístico de la artista. Y escribe:

"La broma lingüística bordada en el vestido expresa el sentimiento de gratitud y pena que Louise siente por su padre. El lugar especial que ella ocupa en el corazón del abrigo tendería a probar que su liberación es al fin completa. 'La niña se ha convertido en adulta" explica Bourgeois "y finalmente descubre pasión en lugar de terror'. Esta pasión es evocada por la presencia de "Trani Episode". De hecho parecería que "Precious Liquids" es un lugar donde Bourgeois tuvo una experiencia afectiva, como pondría de manifiesto su naturaleza maternal y tranquilizadora ..." (Bernadac, 1996: 135).

La antigua niña es ya una adulta, su (com)pasión es maternal, y su liberación es completa: el suyo es pues un renacimiento personal y artístico.

Pollock, por su parte, en desacuerdo con las tendencias esencialistas de la lectura de Bernadac, señala que Rosalind Krauss, al menos, contribuyó a situar al obra de Bourgeois en fructífero debate frente a la de Duchamp y en concreto frente a una de sus obras canónicas, "Large Glass". La interpretación de Bernadac, a su juicio, dota a la instalación de Bourgeois de un contenido específico que viene, por otra parte, a reconfirmar el falocentrismo de la "bachelor machine" de Duchamp a

4 Cualquier sencilla identificación de la personalidad artística de Duchamp con la masculinidad es, en si misma, problemática, como ha puesto de manifiesto Amelia Jones (1994). 
riesgo de suscribir la analogía entre lo femenino y el "otro" lado de la diferencia sexual en el que quedaría relegado el trabajo de la artista francesa. La oposición binaria quedaría pues: masculino $=$ fálico/femenino=materno. A juicio de Pollock, ni Bourgeois ni Duchamp invocan un cuerpo anatómico sino una corporeidad que se manifiesta por medio de una serie de complejos mecanismos, recipientes, emanaciones y líquidos, que desplaza los tropos establecidos en la tradición para aludir al cuerpo y al deseo tomando precisamente de la imaginería de la modernidad mecanicista nuevos elementos y procesos de significación. En cualquier caso, Pollock quiere dejar claro que Bourgeois consigue algo bien diferente de Duchamp, algo que sitúa a lo femenino más allá de la provocación del gesto falocéntrico visual de Duchamp. Esta diferencia "no fálica" que Pollock articula con ayuda de Bourgeois sigue remitiendo de manera subversiva al cuerpo.

La instalación "Precious Liquids" se nutre de asociaciones metafóricas elaboradas a lo largo de más de cincuenta años de producción artística. El tonel de madera del tamaño de una habitación que rodea a la instalación es una gran caja surrealista. Como las imágenes del expresionismo abstracto de profundidades acuáticas, evoca el paso a través de las profundidades del espacio como algo análogo al paso por las profundidades del tiempo. Nos atrae hacia un espacio que significa tanto el interior de un cuerpo como el de un espacio psíquico (Pollock, 199: 76).

La ausencia de un entramado crítico capaz de incorporar la escultura de Louise Bourgeois se debe en no pequeña parte a las terribles implicaciones de estas metáforas. Si bien es cierto que el arte surrealista y el expresionismo abstracto proyectan el self no racional sobre los otros "primitivos" y "mujeres", y que la teoría formalista niega a la materia toda metaforicidad, también la teoría feminista trasluce ansiedades al enfrentarse con el sujeto post-Cartesiano. Desde la postguerra hasta la actualidad, no obstante, estos temas reprimidos, retornan de múltiples formas, tanto representacionales como abstractas, confrontándonos con los límites de nuestros poderes racionales para comprehender un self que excede a la racionalidad.

Cualquier encuentro con el arte de Bourgeois puede dejar a la espectadora en suspenso en un espacio misterioso y liminal. Es el espacio de la exploración sensorial en un medio abierto y no acotado, un espacio ocupado por infinidad de objetos de toda índole así como por una gran diversidad de aspectos del ser o de la identidad. Hablamos pues de un espacio de placer, expansivo, de límites personales que se desdibujan y se diluyen, espacio también donde la integridad física corre peligro de hundirse en un vacío insondable que puede traer consigo su desaparición. 
La crítica de arte feminista se propone restaurar al dominio del arte lo que le fue arrebatado por la retórica modernista: el sentido del ser encarnado, y el sujeto del deseo, así como el de la agresividad y la violencia. Bourgeois ha sido valorada por las jóvenes artistas y críticas por haber sacado a la luz todos estos temas en su práctica artística. Sin embargo, como también se ha observado, el descubrimiento de Bourgeois por las feministas en los años 70 no ha dado como resultado una reacción acorde con lo que sus planteamientos idiosincráticos hubiesen hecho esperable. Uno de los motivos que pueden explicar esta falta de reacciones y debates puede deberse a la consabida ausencia de críticas mujeres y a la escasa presencia de mujeres en la historia del arte de los años cuarenta y cincuenta cuando Bourgeois comenzó su andadura. Es posible también que la aproximación monográfica a la historia del arte pura y simplemente no dé cuenta de un proyecto apropiado y socialmente consciente que busque someter a reto a las jerarquías profesionales muy establecidas. Por último, también nos queda la duda de si la teoría propiamente feminista ha escapado por completo de la angustia del modernismo frente a un sujeto encarnado que se sitúa a ambos lados de la racionalidad. La proyección futura de la obra de Bourgeois, así como las innovadoras propuestas de tantas artistas emergentes hoy que, sin duda, hallarán en sus creaciones inspiración y provocación, deberán dar respuesta a tales incertidumbres para mantener vivo y en proceso el edificio de la creación y la crítica feminista.

\section{BIBLIOGRAFÍA}

ACOCELLA, JOAN (2002): The Spider's Web Louise Bourgeois and Her Art. The New Yorker Feb 4, 72-76.

BERNADAC, MARIE-LOUISE (1996): Louise Bourgeois. Paris: Flammarion.

BERNADAC, MARIE-LOUISE, H.U. OBRIST (1998): Louise Bourgeois. Destruction of the Father Reconstruction of the Father. Writings and Interviews, 1923-1997. London: Violette Editions. Traducido en 2008 como Destrucción del padrel reconstrucción del padre. Escritos y entrevistas 1923-1997. Madrid: Síntesis.

CAVALIERE, BARBARA y ROBERT C. HOBBS (1977): Against a Newer Laocoon. Arts Magazine 51 (8), 110-117.

CHAVE, ANNA C. (1989): Mark Rothko: Subjects in Abstraction. New Haven: Yale University Press.

GIBSON, ANN EDEN (1997): Abstract Expressionism: Other Politics. New Haven: Yale University Press.

GREENBERG, CLEMENT (1955): American-Type Painting. Partisan Review 22 (Spring), 179-196.

GREENBERG, CLEMENT (1965, 1966): Modernist Painting. En Battcock, G. ed., The New Art: A Critical Anthology, 100-110. New York: Dutton. 
JONES, AMELIA (1994): Postmodernism and the Engendering of Duchamp. New York: Cambridge University Press.

KRAUSS, ROSALIND (1989): Portrait of the Artist as Fillette. En Weiermair, P. et al. eds. Louise Bourgeois. Frankfurt: Frankfurter Kunstverein.

LANDAU, ELLEN (1989): Jackson Pollock. New York: Harry Abrams.

LANGHORNE , ELIZABETH L. (1979): Jackson Pollock's "The Moon Woman Cuts the Circle". Arts Magazine 53 (7), 128-137.

LEJA, MICHAEL (1993): Reframing Abstract Expressionism: Subjectivity and Painting in the 1940s. New Haven: Yale University Press.

LIPPARD, LUCY (1975): Louise Bourgeois: From the Inside Out. Artforum 13 (7), 26-33. (March 1975), reprinted in From the Center: Feminist Essays on Women's Art. 238-249. New York: Dutton (1976).

MAYAYO, PATRICIA (2002): Louise Bourgeois. Hondarribia (Guipuzcoa): Nerea.

MEYER-THOSS, CHRISTIANE (1992): Konstruktionen für den freien Fall. Designing for Free Fall. Zurich: Amman Verlag.

NIXON, MIGNON, ed. (1999): Louise Bourgeois, Special Issue. Oxford Art Journal 22 (2).

PIPER, ADRIAN (1994): Statement. En Kodak, C., T. Sultan, y C. Leigh, eds., Louise Bourgeois: The Locus of Memory, Works 1982-1993. 79. New York: The Brooklyn Museum.

POLLOCK, GRISELDA (1999): Old Bones and Cocktail Dresses: Louise Bourgeois and the Question of Age. The Oxford Art Journal 22 (2), 73-100.

SAWIN, MARTICA (1995): Surrealism in Exile and the Beginnings of the New York School. Cambridge, MA: MIT Press.

SCHIMMEL, PAUL, ed. (1986): The Interpretive Link: Abstract Surrealism into Abstract Expressionism, Works on Paper, 1938-1948. Newport Beach, CA: Newport Harbor Art Museum.

SERRA, RICHARD (1994): Rage. En Kodak, C., T. Sultan, y C. Leigh, eds., Louise Bourgeois: The Locus of Memory, Works 1982-1993. 80. New York: The Brooklyn Museum.

WYE, DEBORAH (1982): Louise Bourgeois. New York: The Museum of Modern Art. 